MASERA, Luca. "Evidencia epidemiológica de un aumento de mortalidad y responsabilidad penal. En busca de una clasificación penal para una nueva categoría epistemológica".

Polít. crim. Vol. 12, № 23 (Julio 2017), Art. 12, pp. 428-452. [http://www.politicacriminal.cl/Vol_12/n_23/Vol12N23A12.pdf]

\title{
Evidencia epidemiológica de un aumento de mortalidad y responsabilidad penal. En busca de una clasificación penal para una nueva categoría epistemológica
}

\section{Epidemiological evidence of an increase in mortality and criminal liability. Researching a criminal qualification for a new epistemological category}

\author{
Luca Masera \\ Profesor de Derecho Penal de la Universidad de Brescia \\ luca.masera@unibs.it
}

\section{Resumen}

En el presente artículo se aborda la cuestión de la función que se debería atribuir, en derecho penal, a la evidencia epidemiológica de un exceso de mortalidad en una población expuesta al factor de riesgo representado por sustancias tóxicas utilizadas en un determinado proceso productivo. En primer lugar, se analizan las respuestas que la jurisprudencia italiana ha aportado a esta cuestión, tratando de llegar a la afirmación de responsabilidad penal de los gerentes y/o de algunos de sus subordinados de la empresa donde se utilizan las sustancias tóxicas: el enfoque tradicional que utiliza el conocimiento epidemiológico para demostrar la causalidad individual en procesos por homicidio o lesiones no intencionales, y el enfoque más reciente que utiliza este conocimiento como evidencia del delito de "desastre doloso". Seguidamente, se propone otra solución al problema basada en la imputación de los delitos de homicidio o lesiones mediante el instrumento conceptual de origen alemán de la "determinación alternativa de la víctima" ("Opfer-Wahlfeststellung"), y se analizan las reacciones suscitadas en Italia por esta propuesta. Por último, se proponen reflexiones de síntesis sobre la cuestión analizada.

Palabras clave: Evidencia, epidemiológica, aumento de mortalidad, causalidad, homicidio no intencional, delitos de peligro, determinación alternativa.

\begin{abstract}
The paper relates to the issue of the role attributed in criminal law to the epidemilogical proof of an excess of mortality in a population exposed to a given risk factor. Primarily the author analyses the responses that Italian courts has given to this matter: the traditional approach which uses epidemiological knowledge to prove individual causality in proceedings for manslaughters or unintentional injuries, and the most recent approach which uses this knowledge to prove the crime of "intentional disaster". The paper then puts forward another solution to the problem, founded on the charge of offences of manslaughters or injuries by the instrument of "alternative establishment of the victim", and analyses the reactions raised by this solution. Finally, summary reflections are offered on the criminal-political significance of the issue analysed.
\end{abstract}


MASERA, Luca. "Evidencia epidemiológica de un aumento de mortalidad y responsabilidad penal. En busca de una clasificación penal para una nueva categoría epistemológica".

Key words: Evidence, epidemiological, increase in mortality, causality, manslaughter, crimes of endangerment, alternative establishment.

\section{Introducción.}

En la historia de las ciencias biomédicas, la introducción al método epidemiológico ha supuesto una de las innovaciones más importantes en las últimas décadas. De hecho, hasta la década de los cuarenta, la ciencia médica limitaba el concepto de "causa" a la existencia de una relación determinista entre un factor de riesgo dado y la verificación de un hecho patológico singular. Hoy en día, además de esta acepción individualizadora de las relaciones etiológicas, se utiliza generalmente, tanto en investigación clínica como en salud pública, el instrumento epidemiológico de establecimiento causal que aplica el criterio de conditio sine qua non entre el factor de riesgo y sus consecuencias en la población expuesta. Gracias al uso de un complejo articulado de herramientas lógicas y matemáticas, este instrumento permite identificar relaciones de causa-efecto que, de otro modo, no podrían conocerse si el objeto de observación tan solo fuese el simple hecho dañoso.

En otras palabras, un estudio epidemiológico fiable es capaz de establecer con certeza razonable que un determinado número de individuos expuestos a un factor de riesgo ha contraído una patología precisamente a causa de la exposición, aun cuando le resulta imposible identificar, entre todas las personas enfermas, a aquellas que habrían contraído la enfermedad de todos modos y a aquellas que han caída enfermas precisamente a causa de la exposición. Podemos citar, como ejemplo, la relación entre el humo del tabaco y el cáncer de pulmón. A día de hoy, todavía es imposible determinar si un individuo fumador que ha contraído un cáncer de pulmón hubiera enfermado sin el cigarrillo, ya que el cáncer de pulmón también presenta una incidencia significativa entre los no fumadores. Y aun así, a partir de los estudios básicos de Doll en los años cincuenta, considerados como fundadores de la epidemiología moderna por todos los libros de texto sobre epidemiología, sabemos con absoluta certeza que una parte considerablemente importante de los casos de cáncer de pulmón que afectan a una determinada población (por lo menos el 70\%) no habría desarrollado la enfermedad de no haberse expuesto al riesgo asociado con el humo del cigarrillo.

Por tanto, las capacidades heurísticas del método epidemiológico han llevado a la aparición de un nuevo concepto: el daño a la población, el cual resultaba desconocido cuando se elaboraron las categorías conceptuales en las que se articula la responsabilidad penal en los sistemas jurídicos modernos. El código penal italiano, así como los códigos penales extranjeros, describen la protección de la vida y de la integridad física según delitos de resultado, cuando hay una lesión llevada a una persona determinada, o delitos de peligro, cuando la probabilidad de lesión afecta a un número indeterminado de personas. El daño a la vida o la salud representa, al menos en materia penal, una categoría que se declina únicamente en singular, en el sentido de que el lenguaje penal sólo habla de homicidio o lesiones cuando se establece la causa de muerte o enfermedad de una persona determinada. En cuanto a la salud de la población como un todo, está la categoría del peligro (cuando el factor de riesgo ha afectado a una pluralidad de individuos), pero no la de daño. Si el 
Polít. crim. Vol. 12, No 23 (Julio 2017), Art. 12, pp. 428-452.

[http://www.politicacriminal.cl/Vol_12/n_23/Vol12N23A12.pdf]

peligro se convierte en daño a la vida o a la integridad física de algún individuo determinado, el delito de peligro contra la salud pública está en concurso real con los delitos de homicidio o lesiones. Sin embargo, cuando no es posible identificar por separado a cada víctima, la evidencia del daño causado a una pluralidad de individuos no constituye un resultado gnoseológico considerado por la tradición jurídica del derecho penal.

Ahora bien, si el contenido heurístico típico de los estudios epidemiológicos no encuentra ninguna respuesta inmediata en las categorías penales, ello no quiere decir que la epidemiología haya permanecido ajena al ámbito del derecho penal. Al contrario, en las últimas décadas, el jurista italiano (y más concretamente el penalista) observa cada vez más la realidad a través de los ojos del epidemiólogo. El terreno en el que ha aparecido con más obviedad la necesidad de que el juez penal considere los resultados de la investigación científica de carácter epidemiológico está representado en Italia por los numerosos procesos penales iniciados como resultado de muertes o enfermedades causadas por la exposición a sustancias tóxicas (a menudo, la exposición al asbesto), que se iniciaron en los años ochenta (y actualmente se siguen produciendo) en los tribunales italianos.

Estos procesos casi siempre han tenido como objeto la imputación de patologías oncológicas (en el caso del asbesto, la mesotelioma pleural y el cáncer de pulmón) que, como sabemos, no se pueden explicar según paradigmas individualizantes debido a la complejidad de su red de causalidad. De esta manera, en la mayoría de estos procesos la evidencia a disposición de la parte acusadora sólo está representada por estudios epidemiológicos que destacan la existencia de una relación científica de causalidad entre la exposición (por lo general, de origen ocupacional) a una sustancia química y el aumento de incidencia de enfermedades relacionadas con la sustancia dentro de la población de personas expuestas.

La jurisprudencia italiana en materia de exposición a sustancias tóxicas constituye el terreno primigenio del intento de transposición del concepto epidemiológico de "causa" en el seno de las categorías conceptuales del derecho penal. Ello no quiere decir que la jurisprudencia italiana se haya atribuido esta tarea de forma explícita y consciente. Por el contrario, se observa que en un principio, e incluso hoy en día en ciertos aspectos, la especificidad gnoseológica de la evidencia epidemiológica no se desprende claramente de las sentencias de los jueces italianos, que a menudo demuestran no tener un conocimiento preciso del contenido heurístico de esta disciplina científica. Las características del sistema jurídico italiano simplemente han llevado a la opción de atribuir la responsabilidad de las enfermedades oncológicas provocadas por sustancias químicas al ámbito de la responsabilidad penal y no al de la responsabilidad civil (como es el caso en la mayoría de los otros sistemas jurídicos). Esta elección ha provocado que la jurisprudencia italiana haya sido la primera en decidir concretamente sobre la posibilidad o no de subsumir, en delitos penales, la evidencia de un daño a la población establecido por estudios epidemiológicos.

En esta breve investigación no pretendemos ahondar demasiado en los problemas surgidos en la jurisprudencia y la doctrina con respecto a la configuración de la responsabilidad penal que resulta de la exposición a sustancias tóxicas. Los temas son muchos y bastante complejos (tanto en el aspecto de la imputación objetiva como en el del elemento 
MASERA, Luca. "Evidencia epidemiológica de un aumento de mortalidad y responsabilidad penal. En busca de una clasificación penal para una nueva categoría epistemológica".

intelectual del delito), y para una reconstrucción analítica únicamente podemos referirnos a las numerosas y valiosas contribuciones de la doctrina italiana en la materia.

Nuestro recorrido por el debate se orienta más bien hacia un objetivo específico: queremos entender cómo la jurisprudencia, a pesar de la ausencia de una reflexión profunda sobre el tema, ha podido proporcionar una forma jurídica a la evidencia epidemiológica. Creemos que esta lectura es especialmente interesante, ya que incorpora un aspecto que va más allá del ámbito específico de las enfermedades ocupacionales en el sistema penal italiano.

La investigación epidemiológica destaca, cada vez con más frecuencia, casos de exceso de mortalidad etiológicamente atribuible a un comportamiento humano que, de distintas formas, influye en el estado de salud de una población. El contexto que se estudia con más frecuencia (para el que el nivel de análisis es más avanzado y, por tanto, las relaciones causales son más fiables) es el aumento de la mortalidad como resultado de factores de contaminación ambiental. Las investigaciones científicas sobre los efectos en la población de una determinada fuente contaminante en el medio laboral o ambiental son tan abundantes a nivel internacional que permiten identificar, desde hace algunas décadas, áreas específicas de investigación epidemiológica (epidemiología ocupacional y ambiental) ${ }^{1}$.

Hasta ahora, el obstáculo que ha impedido iniciar, fuera de Italia, procesos penales para imputar a los responsables de la exposición los daños causados a la salud de la población ha sido, en primer lugar, la dificultad de identificar los delitos en los que incluir estos casos. La pregunta que debemos responder previamente es el hilo conductor del presente trabajo: ¿el hecho, científicamente establecido de manera fiable, que provocó un aumento en la incidencia de mortalidad debido a una exposición determinada, define o no los elementos de un ilícito penal? De ser así, ¿se deberían imputar delitos que atentan contra la vida y la integridad física, o delitos de peligro contra la seguridad o la salud pública? El sistema italiano es el primero y, hasta donde se sabe, el único en el que la jurisprudencia penal ha abordado este problema ( $\mathrm{y}$, sobre todo, con relación a un gran número de procesos) constituyendo así pues un laboratorio muy interesante para evaluar las posibles soluciones a un problema que, dada la sensibilización creciente en materia ambiental, probablemente tendrá que analizarse en otros países fuera de Italia.

En los apartados 2 y 3 se hace un análisis crítico de las respuestas que la jurisprudencia italiana ha proporcionado en los últimos veinte años a la cuestión que se debate aquí: veremos cómo, además de la tradicional reconducción del elemento epidemiológico en los delitos de homicidio o lesiones (no intencionales), cada vez es más frecuente que la fiscalía inicie procedimientos penales por delitos dolosos de peligro a la salud pública. En el apartado 4 propondremos otra solución al problema, basada en la imputación de los delitos

\footnotetext{
${ }^{1}$ Para un análisis de los diferentes tipos de investigaciones epidemiológicas y de sus características específicas, cf. por todos GREEN, Michael; FREEDMAN, Michael; GORDIS, Leon, "Reference Guide on Epidemiology", en: FEDERAL JUDICIAL CENTER, Reference Manual of Scientific Evidence, $3^{\mathrm{a}}$ ed., 2011, p. 551 y s.
} 
Polít. crim. Vol. 12, No 23 (Julio 2017), Art. 12, pp. 428-452.

[http://www.politicacriminal.cl/Vol_12/n_23/Vol12N23A12.pdf]

de homicidio o lesiones mediante el instrumento de la determinación alternativa de la víctima, y analizaremos las reacciones suscitadas por esta doctrina. En el último apartado se incluye un resumen de lo expuesto a lo largo de esta investigación.

\section{La clasificación como homicidio o lesiones y las dificultades para establecer la causalidad individual.}

La jurisprudencia penal italiana tuvo que enfrentarse por primera vez al conocimiento epidemiológico a principios de los años noventa por los casos de trabajadores expuestos al polvo de amianto, que habían contraído enfermedades oncológicas de las vías respiratorias (mesotelioma pleural y cáncer de pulmón) conocidas por su incidencia significativamente mayor en los individuos expuestos a esta sustancia.

Los primeros posicionamientos de la jurisprudencia valoran el dato epidemiológico por su capacidad de explicar el hecho singular de la enfermedad o muerte. De hecho, como ya hemos mencionado varias veces, la epidemiología presenta una característica metodológica muy específica, que estudia las relaciones etiológicas a nivel poblacional y no a nivel individual. Sin embargo, la constatación del aumento en la incidencia de una patología en una población de individuos expuestos también significa, a nivel del individuo, que la exposición presenta un aumento de riesgo de contraer la enfermedad. Se trata de diversas formas que expresan los mismos datos científicos. La constatación de una relación epidemiológica sustancia-enfermedad se puede expresar mediante un indicador referente a la población (en términos técnicos, es lo que se conoce como riesgo atribuible; es decir, el porcentaje de casos patológicos atribuibles a la exposición) o un indicador referente al individuo (el riesgo relativo; es decir, el aumento del riesgo de contraer la patología en la persona expuesta).

Implícita y naturalmente, por así decirlo, los jueces italianos se orientaron, en primer lugar, hacia el uso de este último indicador para trasladar el conocimiento epidemiológico a los procesos penales. Los primeros procesos se centraban en un pequeño número de casos de trabajadores enfermos, a diferencia de las grandes cantidades (que se cuentan por decenas o cientos) de trabajadores, que se tratarán a continuación. La solución más sencilla consiste en imputar delitos de homicidio o lesiones (imprudentes), teniendo en cuenta que el aumento del riesgo de contraer la patología para cada individuo expuesto es suficiente para imputar el resultado dañoso efectivamente acaecido. Al valorar las particularidades estructurales de la causalidad en los delitos de omisión, la jurisprudencia de principios de los años noventa afirma que la constatación de un aumento del riesgo, para cada individuo expuesto, de desarrollar la enfermedad debido a la omisión por parte del contratante de las medidas de precaución en el lugar de trabajo previstas por ley, equivaldría a demostrar la conditio sine qua non de la omisión con relación a cada caso individual de enfermedad. Por tanto, la información epidemiológica de un aumento del riesgo relativo se considera como evidencia de la derivación causal del hecho singular constitutivo del elemento material de 
MASERA, Luca. "Evidencia epidemiológica de un aumento de mortalidad y responsabilidad penal. En busca de una clasificación penal para una nueva categoría epistemológica".

los delitos de homicidio o lesiones. Esta fue la primera respuesta a la llegada de la epidemiología a los procesos penales ${ }^{2}$.

Desde su aparición, esta interpretación ha sido objeto de duras críticas por parte de la doctrina. Para importantes comentaristas, resultaba evidente que la identificación del criterio penal de imputación causal en el aumento del riesgo implicaba una grave violación de la garantía ligada a la fórmula de la conditio sine qua non. Reemplazar el criterio ex post de la conditio sine qua non por el parámetro pronóstico del aumento de riesgo significa transformar subrepticiamente los delitos de daño, como el homicidio, en delitos de peligro que no condenan el haber causado un hecho dañoso, sino el haber aumentado el riesgo de que se produzca tal hecho ${ }^{3}$.

El momento crucial que marcó el inicio del alejamiento jurisprudencial de esta posición coincide precisamente con uno de los procesos más importantes en materia de enfermedades del trabajo: el proceso del Petrolchimico de Porto Marghera ${ }^{4}$. Mediante la aplicación, como imputación causal, del criterio del aumento de riesgo, la Fiscalía de Venecia instruyó en 1998 un amplio proceso en el que, junto a otros delitos, los más altos empresarios de la industria química italiana fueron acusados de homicidio no intencional de cientos de trabajadores que habían contraído patologías oncológicas (angiosarcoma y cáncer de hígado), de las cuales se conoce la correlación epidemiológica con la sustancia tóxica presente en el lugar de trabajo (el cloruro de vinilo monómero, CVM).

El proceso tuvo una cobertura mediática a gran escala: el número de víctimas y la reputación de las personas procesadas despertaron por primera vez la atención de la opinión pública sobre el tema de la respuesta penal al fenómeno de las enfermedades laborales. Entre la defensa, figuraban algunos de los más renombrados abogados penalistas italianos; entre ellos, el profesor Federico Stella, uno de los mejores expertos en materia de causalidad penal, que en 2001 publicó una monografía que marcó un antes y un después en el debate.

Inspirándose en la literatura norteamericana, el autor adoptó un modelo bifásico de establecimiento del nexo causal, sobre la base de la distinción entre "nexo de causalidad general" (o capacidad dañosa o aumento de riesgo)" y "nexo de causalidad específica o singular". Para Stella, una conducta puede considerarse penalmente como causa de un daño

\footnotetext{
${ }^{2}$ Para un análisis de las sentencias que asumieron esta interpretación, consultar MASERA, Luca, "Nesso di causalità e malattie professionali e nella giurisprudenza penale: un difficile equilibrio tra tutela dei lavoratori e garanzie dell'imputato", en: GUAGLIANONE, Luciana; MALZANI, Francesca (Dirs.), Come cambia l'ambiente di lavoro, Milano: Giuffrè, 2007, p. 156.

${ }^{3}$ Para un análisis crítico y exhaustivo de esta interpretación, cf. por todos PALIERO, Carlo Enrico, "La causalità dell'omissione: formule concettuali e paradigmi prasseologici”, Riv. it. med. leg. 1992, p. 821, y DONINI, Massimo, "La causalità omissiva e l'imputazione "per l'aumento del rischio" - Significato teorico e pratico delle tendenze attuali in tema di accertamenti eziologici probabilistici e decorsi causali ipotetici", Riv. it. dir. proc. pen. (1999), p. 32.

${ }^{4}$ Es una de las fábricas más grandes en la industria química italiana, fundada cerca de Venecia a principios de los años cincuenta del siglo pasado.
} 
Polít. crim. Vol. 12, No 23 (Julio 2017), Art. 12, pp. 428-452.

[http://www.politicacriminal.cl/Vol_12/n_23/Vol12N23A12.pdf]

a la vida o a la salud, únicamente si se aporta la evidencia, más allá de toda duda razonable, de que este fue la conditio sine qua non del hecho patológico o letal singular. De esta manera, la evidencia epidemiológica podría utilizarse para establecer el nexo de causalidad general, pero no es suficiente para afirmar una relación etiológica relevante desde la perspectiva del derecho penal, ya que se centra en los efectos que la exposición ha causado en las poblaciones, y no en los individuos singulares expuestos y, por lo tanto, no puede, por definición, determinar el establecimiento del nexo de causalidad individual en el que se materializa la conditio sine qua non en materia penal. Aunque parezca que la sustancia tóxica ha causado un aumento significativo de la mortalidad en individuos expuestos, ello no es suficiente para fundamentar una sentencia condenatoria, ya que es imposible identificar a los individuos, entre todos los que han contraído la patología correlacionada con la sustancia, que han desarrollado la enfermedad precisamente por haber estado expuestos. Con una fórmula sintética pero eficaz se puede decir que "la epidemiología es útil, pero no es suficiente" para establecer un nexo de causalidad relevante en materia penal ${ }^{5}$.

Pocos meses después de la publicación del libro de Stella, en la sentencia dictada por el Tribunal de Venecia ${ }^{6}$ en el caso de Porto Marghera se adoptó la posición descrita en el libro, absolviéndose a los directivos de Petrolchimico procesados por homicidio, debido precisamente a la falta de evidencia de un nexo causal entre la exposición y cada caso individual de enfermedad o muerte.

Las posiciones de Stella pronto se confirmaron en algunas sentencias de la Corte de Casación en que, además de calificar de insuficiente el criterio del aumento del riesgo en la acreditación de la causalidad penal, se afirmó que esta debía basarse exclusivamente en leyes científicas con un coeficiente probabilístico cercano al 100\%, rechazándose así la responsabilidad penal en la imputación de las enfermedades laborales ${ }^{7}$.

La evidente distancia entre la posición del aumento de riesgo, predominante en los años noventa, y la nueva posición de probabilidad al 100\%, se acortó en 2002 gracias las Cámaras reunidas de la Corte de Casación con la famosa sentencia Franzese ${ }^{8}$, que aun hoy constituye una parada obligatoria para cualquier juez italiano que se enfrente a la cuestión de la causalidad. La sentencia ofrece una gran cantidad de ideas interesantes en las que no podemos profundizar aquí. En cuanto a la cuestión específica de la función de la epidemiología en derecho penal, si bien las cámaras reunidas se abstuvieron de pronunciarse ex professo sobre el tema ${ }^{9}$, parecían compartir la limitación de la

\footnotetext{
${ }^{5}$ Para esta cuestión, vid. especialmente la parte II (titulada I tentativi di flessibilizzazione del diritto penale d'evento e l'impossibilità di una tutela penalistica delle vittime della società del rischio) del libro de STELLA, Federico, Giustizia e modernità - La protezione dell'innocente e la tutela delle vittime, Milano: Giuffrè, 2001.

${ }^{6}$ Tribunal de Venecia, 2.11.2001, Cefis, Cass. pen., 2003, p. 267.

${ }^{7}$ Cf. en particular Cass. 13.2.2002, Covili, Riv. it. dir. proc. pen., 2002, p. 737.

${ }^{8}$ Cass. S.U. 10.7-10.9. 2002, Franzese, Riv. it. dir. proc. pen., 2002, p. 1133.

${ }^{9}$ Cabe recordar que la sentencia se refería a un caso de negligencia médica y no de enfermedades ocupacionales, y el conocimiento científico sobre el que se basaba el establecimiento no tenía carácter epidemiológico.
} 
MASERA, Luca. "Evidencia epidemiológica de un aumento de mortalidad y responsabilidad penal. En busca de una clasificación penal para una nueva categoría epistemológica".

consideración de la evidencia epidemiológica congelada en la fórmula "es útil, pero no suficiente". De hecho, el modelo heurístico desarrollado en 2002 por la Corte de Casación permite al juez recurrir a las leyes epidemiológicas en la evaluación del nexo de causalidad, en el sentido de que incluso las leyes científicas de (bajo) contenido probabilístico, como las de la epidemiología, puedan tenerse en cuenta al evaluar el nexo de causalidad general (por tanto, se rechaza la posición "extrema" del 100\%). Sin embargo, para determinar con certeza el nexo de causalidad, es necesaria la prueba de que la aparición de la patología individual no puede proceder de ninguna posible explicación alternativa, y el juez necesita entonces una evidencia individualizante que la epidemiología no puede ofrecer.

Tras la sentencia Franzese, ya no se acepta, por lo menos en principio, la posibilidad de establecer el nexo de causalidad sobre la base de un solo parámetro epidemiológico del aumento del riesgo (para el individuo singular expuesto) de contraer la enfermedad, sin pasar por un análisis ex post de la posibilidad de imputación de la enfermedad de un individuo determinado únicamente a la exposición y a ningún otro factor de riesgo.

La sentencia Cozzini $^{10}$ pronunciada por la Corte de Casación en 2010, en materia de patologías relacionadas con la inhalación de asbesto, constituye la exposición más esclarecedora y consumada del modelo de establecimiento etiológico adoptado hoy en día por la jurisprudencia de casación y de la función del conocimiento epidemiológico dentro de dicho modelo. Incluso cuando la existencia de una correlación epidemiológica sustanciapatología parezca cierta, a nivel de causalidad general, para el derecho penal el establecimiento del nexo de causalidad relevante debe basarse en la evaluación de una elevada probabilidad lógica con respecto a la imputación a la sustancia de un resultado singular (nexo de causalidad individual).

Resulta evidente que este modelo de establecimiento del nexo causal complica enormemente la tarea de la acusación. Cuando la patología que se imputará es multifactorial (como la mayoría de las patologías oncológicas), o cuando se trata de patologías monofactoriales (como la mesotelioma pleural objeto de la sentencia Cozzini), pero el acusado es únicamente responsable de una fracción temporal de la exposición (ya que durante la vida laboral de la víctima varios individuos han estado a la cabeza de la empresa), el ministerio público se encontrará en una situación muy difícil: no será suficiente establecer la correlación epidemiológica entre la sustancia y la patología en cuestión, y será necesario demostrar que la patología singular no es atribuible a ningún otro factor de riesgo más que el profesional (un ejemplo clásico es el humo del cigarrillo para el cáncer de pulmón), o que la extensión de la exposición ha acelerado el progreso de la patología singular (en caso de sucesión en el tiempo de los individuos responsables de la exposición).

La cuestión está lejos de llegar a un punto final estable en la jurisprudencia. Al escribir este artículo (septiembre de 2016), decenas de procesos penales por homicidio y lesiones

\footnotetext{
${ }^{10}$ Cass., sec. IV, 17.9.2010, Cozzini, n. 43786, Dir. pen. cont., 11.1.2011.
} 
Polít. crim. Vol. 12, No 23 (Julio 2017), Art. 12, pp. 428-452.

[http://www.politicacriminal.cl/Vol_12/n_23/Vol12N23A12.pdf]

culposos por enfermedades del trabajo (en su mayoría relacionadas con el amianto) están en curso en los tribunales de toda Italia. El modelo desarrollado por la sentencia Cozzini subyace a muchas resoluciones absolutorias motivadas por la imposibilidad de establecer el nexo de causalidad a nivel individual. Asimismo, hay sentencias que, con la categoría de causas concomitantes o aprovechando del alcance semántico del criterio de la elevada probabilidad lógica, conducen a decisiones condenatorias.

En este trabajo no podemos detenernos en estos temas ${ }^{11}$. En cualquier caso, y es esto lo que queremos destacar, la evidencia epidemiológica según la que la sustancia ha provocado un exceso de mortalidad no es suficiente, de acuerdo con el modelo individualizante adoptado por la jurisprudencia a partir de la sentencia Franzese, para el establecimiento del nexo causal necesario para imputar la responsabilidad por delitos de homicidio o lesiones (culposas).

\section{La clasificación como delitos dolosos de peligro para la salud pública.}

En los últimos años, la jurisprudencia ha iniciado un camino diferente al mencionado anteriormente, dando importancia a la evidencia epidemiológica, ya no en la perspectiva de establecer nexos de causalidad individuales relevantes para los delitos de homicidio o lesiones (culposas), sino como elemento sobre el cual basar el establecimiento de un peligro para la salud pública, pertinente para la integración de los delitos (dolosos) cometidos contra la seguridad o salud pública.

El leading case de esta nueva posición, de la que ahora debemos ocuparnos, es sin duda el proceso conocido como el caso Eternit, en el que se procesó a dos empresarios (uno belga y otro suizo) que durante los años 50-80 fueran los administradores de los grupos multinacionales que tenían el control de la empresa Eternit, el mayor productor italiano de asbesto.

La evidencia científica sobre la que se basó el proceso es similar, en cuanto a lo que nos interesa en este trabajo, a la de los procesos "clásicos" descritos en el párrafo anterior: varios estudios epidemiológicos convergentes demostraron, en los individuos que vivían o trabajaban cerca de las fábricas del grupo Eternit, un aumento drástico en la incidencia de varias patologías para las que se estableció una correlación epidemiológica con la exposición al asbesto (en especial, mesotelioma pleural y cáncer de pulmón).

En lugar de imputar a los responsables de la exposición por delitos de homicidio o lesiones imprudentes, como era habitual en este tipo de situaciones, la Fiscalía de Turín decidió, por

\footnotetext{
11 Para una panorámica de esta problemática, cf. ex multis, y sin ninguna pretensión de exhaustividad, BARTOLI, Roberto, "La recente evoluzione giurisprudenziale sul nesso causale nelle malattie professionali da amianto", Dir. pen. cont., N ${ }^{\circ} 3-4$ (2014); CENTONZE, Francesco, "Il problema dell'accertamento del nesso di causalità tra esposizione professionale ad amianto e mesotelioma pleurico", Riv. it med. leg. $\mathrm{N}^{\circ} 3$ (2012), p. 1523; ZIRULIA, Stefano, "Ancora oscillazioni nella giurisprudenza di legittimità sulle "morti da amianto",, Dir. pen. cont., 11.10.2012.
} 
MASERA, Luca. "Evidencia epidemiológica de un aumento de mortalidad y responsabilidad penal. En busca de una clasificación penal para una nueva categoría epistemológica".

primera vez, imputar el delito de "desastre doloso"" . La intención de la Fiscalía era evidente. La adopción de la solución tradicional habría implicado la necesidad de establecer la derivación causal del asbesto para cada una de las cientos de muertes que, de acuerdo con los resultados de estudios epidemiológicos, se correlacionaban con la sustancia: un proceso muy largo y agotador, tras el cual, incluso si se admitía el establecimiento de un nexo de causalidad para, al menos, algunas de las víctimas, nos habríamos enfrentado a un riesgo concreto de declaración de extinción del delito por prescripción, al menos para las muertes menos recientes ${ }^{13}$. Por tanto, en los cargos, el exceso de mortalidad debido al asbesto no se reflejó en la imputación de un número de homicidios (culposos) proporcional al número de víctimas, sino que fue utilizado exclusivamente para mantener integrada la circunstancia agravante especial de la verificación del desastre doloso (art. 434, párrafo 2 del Código Penal italiano).

En otras palabras, la imputación se realizó sobre la base de un delito de peligro para la seguridad o salud pública, para el que no es necesario aportar la prueba de un nexo de causalidad individual para cada patología, ya que es suficiente con proporcionar la evidencia científica de que la sustancia (asbesto) es peligrosa para la salud pública. Sin embargo, desde que los estudios epidemiológicos en la población de individuos expuestos demostraron no sólo un peligro para las personas expuestas, sino también un exceso de mortalidad para todas las principales patologías correlacionadas con el asbesto, en los cargos la lista de los nombres de todos los fallecidos o afectados por la enfermedad se tradujo en la incriminación del delito previsto en el art. 434 en su forma agravada a partir de la verificación del desastre (que consistió, según la acusación, en la propagación de asbesto en el medio ambiente y en las muertes que la sustancia causó en la población).

La sentencia en primera instancia ${ }^{14}$ dio lugar a penas especialmente severas (16 años de prisión para los dos acusados).

Al reducir el análisis al problema que nos interesa aquí, la función de la evidencia epidemiológica del exceso de mortalidad en la evaluación relativa al art. 434 del Código Penal es muy limitada. Al adoptar los criterios esenciales del concepto de desastre establecido por la jurisprudencia constitucional ("evento destructivo de proporciones extraordinarias que haya causado un peligro para la vida o la integridad física de un número

\footnotetext{
${ }^{12}$ Se trata del delito de disastro innominato doloso, sancionado en el art. 434 del Código Penal: "1. Chiunque commette un fatto diretto a cagionare il crollo di una costruzione o di una parte di essa ovvero un altro disastro è punito, se dal fatto deriva pericolo per l'incolumità pubblica, con la reclusione da uno a cinque anni. 2. La pena è della reclusione da tre a dodici anni se il crollo o il disastro avviene". La Fiscalía había imputado también el delito de omisión intencional de medidas de precaución en el lugar de trabajo (art. 437 del Código Penal), que fue declarado prescrito por la Corte de Apelación: por razones de brevedad, nos ocuparemos solo de la imputación de desastre, que resulta de mayor interés a la perspectiva propia de esta investigación.

${ }^{13}$ Para esta cuestión, cf. ZIRULIA, Stefano, "Caso Eternit: luci ed ombre nella sentenza di condanna in primo grado", Riv. it. dir. proc. pen., Vol. 56, $\mathrm{N}^{\circ} 1$ (2013), p. 489.

${ }^{14}$ Trib. Turin, 13.2.2012, Dir. pen. cont., 30.5.2012.
} 
Polít. crim. Vol. 12, No 23 (Julio 2017), Art. 12, pp. 428-452.

[http://www.politicacriminal.cl/Vol_12/n_23/Vol12N23A12.pdf]

indeterminado de personas" ${ }^{\text {15 }}$ ), el Tribunal incluyó los elementos de dicho concepto en la contaminación ambiental causada por las fábricas de Eternit. El elemento del exceso de mortalidad se utiliza únicamente para considerar, casi como obiter dictum, que "el caso tratado no solo presenta la ocurrencia de un peligro grave y desproporcionado para la seguridad y la salud de un número indeterminado de personas, ya de por sí suficiente para establecer la contaminación ambiental: de hecho, en nuestro caso, el desastre ambiental produjo una serie verdaderamente importante de daños a personas en todos los lugares afectados".

La sentencia de la Corte de Apelación ${ }^{16}$ (que dio lugar a un fallo incluso más severo, de 18 años de prisión) presenta, también con respecto al tema que aquí nos ocupa, una interesante novedad. En su sentencia, la Corte de Apelación sostiene que el concepto de desastre no se agota, como había mantenido el Tribunal, en la contaminación ambiental (immutatio loci) que ocasiona un peligro para la salud pública. La sentencia establece que "otro componente del hecho de desastre objeto del presente proceso está representado por el fenómeno excepcional de carácter epidémico que el escrito de cargos considera haberse manifestado durante un largo tiempo". Por lo tanto, el exceso de mortalidad y morbilidad (que la sentencia define como "fenómeno epidémico") ya no constituye, como en primera instancia, una simple consecuencia posterior al desastre, irrelevante a efectos de la clasificación jurídica de los hechos, sino que representa un elemento constitutivo del hecho-desastre en el que se materializa el elemento objetivo del supuesto delito. Con relación al hecho descrito anteriormente, la Corte de Apelación establece el nexo de causalidad según el razonamiento contrafáctico tradicional, pero este nexo ya no se refiere a los hechos patológicos singulares, sino al hecho compuesto por el exceso de patologías. Por tanto, con relación a este hecho los estudios epidemiológicos son suficientes para establecer la causalidad según la fórmula de la conditio sine qua non (la sentencia introduce el concepto de causalidad colectiva).

La Corte de Casación, en una sentencia que causó sensación en los medios, revocó la condena de la Corte de Apelación, con el argumento de que el delito de desastre prescribio $^{17}$. El punto crucial hace referencia al concepto de desastre y a la posibilidad de reconducir en este concepto las muertes establecidas sobre la base de los estudios epidemiológicos. La Corte de Casación no comparte con la Corte de Apelación el argumento según el cual el fenómeno epidémico representado por el aumento de la mortalidad es un elemento constitutivo del concepto de desastre, y dice, en cambio, que las muertes no son un elemento del desastre, sino más bien una consecuencia nefasta del mismo, y que no son relevantes para la clasificación jurídica de los hechos. Esta reconstrucción es crucial para determinar si el delito se considera o no prescrito. La Corte de Apelación, estimando las muertes causadas por el amianto como elemento del desastre, había dictaminado que, mientras las personas sigan muriendo a causa de enfermedades relacionadas con el asbesto, el delito debe considerarse aún en fase de comisión. Por el contrario, la Corte Suprema señaló que el desastre consistió únicamente en la

\footnotetext{
${ }^{15}$ Trib. Const., n. 327/2008.

${ }^{16}$ Tribunal de Apelación de Turín, 3.6.2013, Dir. pen. cont., 18.11.2013.

${ }^{17}$ Cas., sec. I, 23.2.2015, n. 7941, Dir. Pen. Cont., 24.2.2015.
} 
MASERA, Luca. "Evidencia epidemiológica de un aumento de mortalidad y responsabilidad penal. En busca de una clasificación penal para una nueva categoría epistemológica".

contaminación del medio ambiente, y que debe considerarse que dicha conducta concluyó cuando cerraron las plantas (1986). Por ello, al adoptar las normas generales del Código Penal para calcular los plazos de prescripción de los delitos, el delito de desastre prescribió incluso antes de que se iniciara el juicio ante el Tribunal.

Nos hemos detenido en las sentencias sobre el caso Eternit, ya que fueron las primeras que motivaron ampliamente la subsunción de la evidencia epidemiológica en los delitos cometidos contra la salud pública. Dicha clasificación fue adoptada por muchas otras fiscalías, que han aplicado este modelo en varios procedimientos (en su mayoría, todavía están en fase de investigación preliminar), algunos de los cuales han tenido un impacto mediático de gran magnitud.

El caso más llamativo es el del polo siderúrgico de Taranto. Un peritaje epidemiológico llevado a cabo por orden del juez estableció un aumento significativo en la incidencia de varias patologías en las personas que vivían en barrios de la ciudad adyacentes a la enorme planta industrial y, por lo tanto, particularmente expuestos a las emisiones nocivas (se trata de una de las acererías más grandes de Europa, con una extensión dos veces mayor a la ciudad de Taranto). Sobre la base de este peritaje, en julio de 2012, la Fiscalía de Taranto solicitó y obtuvo del juez de la investigación preliminar (GIP) la incautación de áreas enteras de la instalación (así como la detención cautelar de los propietarios y gerentes de la misma), al considerar que el aumento de la mortalidad comprobada por el peritaje demostraba la comisión del delito de desastre ${ }^{18}$.

Un caso similar y bien conocido fue el de la gran central eléctrica situada en Vado Ligure. En marzo de 2014, la Fiscalía de Savona, tras un peritaje epidemiológico que señalaba la muerte, entre 2000 y 2007, de cientos de personas como consecuencia de patologías atribuibles a las emisiones de la planta, obtuvo del GIP la incautación de dicha instalación y la interrupción de parte importante de la actividad de producción, sosteniendo que este aumento de mortalidad cumplía los elementos del delito de desastre ${ }^{19}$.

La fase aún preliminar de estos procesos (y de otros procesos similares en curso en muchos otros tribunales de la Península) hace que el tema de la clasificación jurídica de la evidencia epidemiológica, que nos interesa aquí y cuya solución determinará el curso del proceso, aún no haya sido objeto de un debate a fondo similar al desarrollado en los juicios de Turín, los cuales se toman como referencia por los redactores de las medidas que deciden las incautaciones.

El marco que está esbozándose en la jurisprudencia aún es incierto. La sentencia de la Corte de Apelación de Turín, que volvió a incorporar el exceso de mortalidad al concepto de desastre, fue contradicha por la Corte Suprema, que indicó claramente que las muertes

\footnotetext{
${ }^{18}$ Para un resumen del procedimiento en curso en Taranto, cf. el artículo de PALMISANO, Stefano, "Del "diritto tiranno" - Epitome parziale di un'indagine su cittadini già al di sopra di ogni sospetto", Quest. giust., $\mathrm{N}^{\circ} 2$ (2014), p. 89; actualmente (septiembre de 2016) el proceso está en curso en el Tribunal de Taranto.

${ }^{19}$ Trib. de Savone, 11.3.2014, Dir. pen. cont., 8.5.2014.
} 
Polít. crim. Vol. 12, № 23 (Julio 2017), Art. 12, pp. 428-452.

[http://www.politicacriminal.cl/Vol_12/n_23/Vol12N23A12.pdf]

son una consecuencia del desastre, no uno de sus elementos constitutivos. Asimismo, en mayo de 2015, el Parlamento aprobó una ley sobre delitos contra el medio ambiente ${ }^{20}$, que define específicamente el delito de "desastre ambiental" (nuevo art. 452 del Código Penal). Sin embargo, también con respecto a la nueva norma, sobre lo que nos concierne, la cuestión es clara: según la Corte Suprema, el exceso de mortalidad no es un elemento del delito de desastre, y la responsabilidad por las muertes únicamente puede establecerse por una condena por el delito de homicidio.

\section{La responsabilidad por homicidio sobre la única base de la evidencia epidemiológica: la teoría de la determinación alternativa de la víctima.}

Antes de que la jurisprudencia abriera el camino para la clasificación de la evidencia epidemiológica como desastre, en 2007 quien escribe elaboró una monografía sobre el tema de la relación entre epidemiología y derecho penal ${ }^{21}$. En esta obra trataba de cuestionar la solidez de la orientación tradicional según la cual, en materia de responsabilidad por los delitos de homicidio y lesiones, la epidemiología "es útil, pero no suficiente". No estaba convencido (y sigo sin estarlo) de que el elemento del exceso de mortalidad, si bien está científicamente probado más allá de toda duda razonable, no era suficiente para establecer el elemento objetivo del delito de homicidio. Y aquí quiero encontrar una solución que, sin perjuicio de los principios de garantía establecidos en materia de causalidad, permita dar relevancia, en materia penal, a la evidencia epidemiológica, incluso cuando no es posible demostrar un nexo de causalidad individual.

En el citado trabajo partí de una constatación obvia: si un estudio científicamente fiable afirma que la exposición a un factor de riesgo ha provocado un aumento de mortalidad, ello significa que un número determinado de personas ha muerto a causa de la exposición. La pregunta que debe hacerse el penalista es la siguiente: ¿es posible que, frente a la evidencia científica de que una exposición ha causado víctimas, el derecho penal no sea capaz de evaluar la responsabilidad con respecto a las muertes provocadas, bajo el único argumento de que no es posible, entre el número total de individuos expuestos que contrajeron la enfermedad, identificar a aquellos que podrían haberse enfermado incluso sin exponerse y a quienes, por el contrario, enfermaron precisamente a causa de la exposición? De todos modos, sabemos con certeza razonable que una parte específica de los individuos cayó enferma y murió precisamente a causa de la exposición. ¿Por qué esta cifra no es suficiente para juzgar la responsabilidad penal referente al hecho-muerte?

La respuesta que aporté en 2007 consistió en suponer que la orientación tradicional no fue impuesta por principios inviolables de garantismo, sino más bien sería el resultado de la dificultad para expresar la cifra heurística propia de la ciencia epidemiológica en las categorías dogmáticas tradicionales de la doctrina jurídica en materia de causalidad. En mi opinión, el instrumento conceptual capaz de superar este obstáculo es la determinación alternativa. Este instrumento, que desde hace mucho tiempo está firmemente arraigado en

\footnotetext{
${ }^{20}$ Ley 22.5.2015, n. 68.

${ }^{21}$ Cfr. MASERA, Luca, Accertamento alternativo ed evidenza epidemiologica nel diritto penale - Gestione del dubbio e profili causali, Milano: Giuffrè, 2007.
} 
MASERA, Luca. "Evidencia epidemiológica de un aumento de mortalidad y responsabilidad penal. En busca de una clasificación penal para una nueva categoría epistemológica".

la doctrina y la jurisprudencia alemanas ${ }^{22}$, y que por el contrario es casi desconocido en la literatura italiana, constituye un instrumento de gestión de la duda en materia de proceso penal y se utiliza cuando los elementos de evidencia demuestran más allá de toda duda razonable la culpabilidad del acusado, pero aún hay incertidumbre con respecto a la reconstrucción del hecho constitutivo del delito. A diferencia de lo que normalmente se produce en caso de duda sobre la reconstrucción de los hechos (y el proceso da lugar necesariamente a la absolución de los acusados, en virtud del principio constitucional de la presunción de inocencia), estos supuestos permiten (y obligan) a llegar, de todos modos, a una sentencia condenatoria, ya que la hipótesis de inocencia del acusado está, sin duda, excluida: en todas las posibles reconstrucciones de los hechos, dicho acusado sin lugar a dudas ha cometido un delito.

El caso típico es el de un individuo que ofrece a la autoridad, en dos ocasiones, diferentes datos sobre su propia identidad. Si es imposible establecer su verdadera identidad, lógicamente, ya no será posible excluir, con razonable certeza, la veracidad de una de sus dos declaraciones (una de las dos declaraciones puede ser verdadera). Por lo tanto, no es posible establecer con cuál de las dos declaraciones el acusado dio una falsa declaración de identidad, pero lo cierto es que, al menos, una de las dos declaraciones es falsa. Así pues, el juez no puede establecer de manera certera el comportamiento por el que el acusado cometió el delito previsto en el art. 495 del Código Penal italiano ("falsa declaración a un funcionario público acerca de su identidad"). Sin embargo, lo cierto es que esta persona ha sido responsable de ese delito por lo menos en una ocasión. Esta situación no da lugar a confusión (no solo en Alemania sino también en la jurisprudencia italiana ${ }^{23}$ ) sobre la legitimidad de una sentencia condenatoria, incluso en ausencia de una identificación unívoca de la conducta culpable.

La categoría de la determinación alternativa de la víctima es una especie del género determinación alternativa. En los casos tradicionales, el objeto de una determinación alternativa es el comportamiento del acusado, como en el caso de las declaraciones falsas recién analizadas. En los casos que nos ocupan, por el contrario, es la víctima de la acción delictiva la que se establece alternativamente (es evidente que se ha causado la muerte de un hombre, pero no sabemos si se trata de la muerte de uno u otro entre varias víctimas). En cualquier caso, la estructura lógica del establecimiento de los hechos sigue siendo la misma: una incertidumbre sobre la reconstrucción del hecho (la víctima del delito solo puede identificarse de una manera alternativa; como en los otros casos de determinación alternativa, la determinación de la conducta culpable es alternativa) que, sin embargo, no

\footnotetext{
${ }^{22}$ El tema de la Wahlfeststellung está presente en los principales manuales y comentarios alemanes de derecho penal, en la parte dedicada al principio de legalidad: cf. ex multis ESER, Albin, "Anhang zu § 1: Wahlfeststellung", en: SCHÖNKE, Adolf; SCHRÖDER, Horst (Dirs.), Strafgesetzbuch Kommentar, München: C.H. Beck, XXV ed., 1997, § 58 ss., y TRÖNDLE, Herbert; FISCHER, Thomas, "§ 1", en: TRÖNDLE, Herbert; FISCHER, Thomas (Eds.), Strafgesetzbuch und Nebengesetze, München: C.H. Beck, XLIX ed., 1999, § $12 \mathrm{ss}$.

${ }^{23}$ Cfr. más precisamente Cass., sec. V, 5.2.2004, Ali Rafour, Diritto \& Giustizia, № 9 (2004), pp. 20 y ss.
} 
Polít. crim. Vol. 12, No 23 (Julio 2017), Art. 12, pp. 428-452.

[http://www.politicacriminal.cl/Vol_12/n_23/Vol12N23A12.pdf]

hace dudar sobre la culpabilidad del acusado o la clasificación jurídica de su responsabilidad.

La tipología de establecimiento basada en el conocimiento epidemiológico, que no viene acompañado por la evidencia de la causalidad individual, encaja a la perfección, en mi opinión, en este esquema conceptual ${ }^{24}$. Cualquier juez que disponga de un estudio epidemiológico válido puede afirmar, más allá de toda duda razonable, que una parte de los individuos que contrajeron la enfermedad no se habría enfermado de no haber estado expuesta. No obstante, no puede identificar con precisión (debido a las limitaciones heurísticas intrínsecas del método de investigación epidemiológico) a aquellos que contrajeron la enfermedad precisamente debido a la exposición ni a aquellos que la hubiesen contraído de todos modos sin exposición. Al adoptar el enfoque tradicional de base individualizante, la única solución posible es la absolución. Sin embargo, desde la perspectiva de la determinación alternativa, es legítimo condenar por homicidio (en el caso en que también se cumpla el elemento subjetivo del delito), incluso en ausencia de una identificación clara de la víctima, dado que de todos modos es científicamente cierto que el comportamiento del acusado causó un número determinado de hechos patológicos, correspondiente a la parte de estos hechos que la evidencia epidemiológica atribuye a la sustancia (en términos técnicos, la parte de riesgo atribuible).

Una vez que se tome esta vía, los pasos lógicos que el juez debe seguir son los que, por lo general, siguen en materia de establecimiento de nexo causal. En primer lugar, es necesario identificar un estudio epidemiológico fiable que establezca la correlación general de la exposición con el aumento de una o más patologías determinadas. Seguidamente, se debe comprobar que el aumento de la incidencia de la patología debido a la exposición, conocido a nivel general, realmente ha tenido un impacto en individuos específicamente expuestos, excluyendo la existencia de cualquier explicación alternativa para el aumento. Por último, es importante identificar la parte de los hechos que, sobre la base de una estimación prudente, sean atribuibles, con razonable certeza, a la exposición. Por lo tanto, la estructura de la imputación causal es la impuesta por Franzese en términos bifásicos (primero, el establecimiento del nexo de causalidad general; y segundo, el de la causalidad en el caso específico): lo que cambia es el objeto de la evaluación contrafáctica, que ya no es el hecho-muerte singular, sino el aumento de la mortalidad en la población, cuyo determinación alternativa permite proporcionar una clasificación autónoma en el derecho penal.

Si han fallecido personas a causa de una conducta humana, la clasificación penal de este comportamiento solo puede ser el homicidio, incluso si es imposible aportar de modo certero los nombres y apellidos de las víctimas. Esa fue la conclusión a la que llegamos en 2007.

\footnotetext{
${ }^{24}$ El uso de la evidencia epidemiológica para la determinación alternativa ya había sido esbozado por la literatura alemana de los años setenta y ochenta en materia de responsabilidad penal con respecto a la experimentación de medicamentos en seres humanos: para un análisis del debate alemán sobre el tema de la Opfer-Wahlfeststellung, consultar MASERA, Accertamento, cit. nota $\mathrm{n}^{\circ}$ 21, p. 299.
} 
MASERA, Luca. "Evidencia epidemiológica de un aumento de mortalidad y responsabilidad penal. En busca de una clasificación penal para una nueva categoría epistemológica".

Mi tesis, según la cual la evidencia epidemiológica puede ser suficiente para establecer el nexo de causalidad pertinente por los delitos de homicidio o lesiones, ha suscitado en la doctrina una multitud de reacciones ${ }^{25}$, en su mayoría críticas. A continuación, analizaremos (e intentaremos refutar) las principales objeciones planteadas en su contra, y después trataremos las contribuciones que se han mostrado de acuerdo con mi posición.

La primera crítica no se centra, en realidad, en el razonamiento jurídico que subyace a mi tesis, sino más bien en un elemento anterior al mismo, a saber, la posibilidad de confiar, en el marco de una evaluación de la responsabilidad penal, en una disciplina científica como la epidemiología que, incluso con relación a los nexos de causalidad a nivel de población y no de individuos, no sería capaz de garantizar un estándar de fiabilidad "más allá de toda duda razonable" ${ }^{26}$.

Evidentemente, me es imposible abordar por completo el tema de la fiabilidad metodológica de la epidemiología y, por lo tanto, no puedo sino remitir al capítulo de mi monografía dedicado a este tema ${ }^{27}$. Sin embargo, considero que esta posición de desconfianza radical con respecto a las capacidades heurísticas de esta disciplina es el resultado de un malentendido entre fiabilidad de la disciplina en sí misma y fiabilidad de cada estudio objeto de los diferentes procesos. En todos los procesos que ya he mencionado, la defensa cuestionó vivazmente la fiabilidad de los estudios sobre los que la parte acusadora basó sus cargos, como sucede, de hecho, en casi todos los procesos donde participa el conocimiento científico. De todos modos, la fiabilidad del método de estudio epidemiológico se ve confirmada por el hecho de que toda la investigación biomédica moderna (desde la experimentación de medicamentos hasta la formulación de protocolos

\footnotetext{
${ }^{25}$ La teoría de la determinación alternativa de la víctima ha sido expresamente objeto de una particular atención por BARTOLI, Roberto, Il problema della causalità penale - Dai modelli unitari al modello differenziato, Torino: Giappichelli, 2010, p. 82; BRUSCO, Carlo, Il rapporto di causalità - Prassi ed orientamenti, Milano: Giuffrè, 2012, p. 212; D’ALESSANDRO, Francesco, “Art. 40”, en: DOLCINI, Emilio; MARINUCCI, Giorgio (Dirs.), Codice penale commentato, Giorgio, Milano: IPSOA, III ed., 2011, p. 411; DELLA BELLA, Angela, "Il problema del nesso causale nel sistema penale e processuale", en: SMURAGLIA, Carlo (Dir.), Le malattie da lavoro, Milano: Hoepli, 2008, p.66; DI GIOVINE, Ombretta, "Probabilità statistica e probabilità logica nell'accertamento del nesso di causalità", Cass. pen. $\mathrm{N}^{\circ} 5$ (2008), p. 2183 ; DONINI, Massimo, "Imputazione oggettiva dell'evento", Enc. dir., Annali, III, Milano: Giuffrè, 2010, p. 703; DONINI, Massimo, "Il garantismo della condicio sine qua non e il prezzo del suo abbandono. Contributo all'analisi dei rapporti fra causalità e imputazione", Riv. it. dir. proc. pen., Vol. 2 (2011), p. 514; GARGANI, Alberto, "La 'flessibilizzazione' giurisprudenziale delle categorie classiche del reato di fronte alle esigenze di controllo penale delle nuove fenomenologie di rischio", Leg. pen., 2011, p. 397; MANNA, Adelmo, "I rapporti tra sapere scientifico e sapere giudiziario", Cass. pen., Vol. XLIX (2009), p. 3636 ; SERENI, Andrea, Causalità e responsabilità penale, Torino: Giappichelli, 2008, p. 355; PERINI, Chiara, Il concetto di rischio nel diritto penale moderno, Milano: Giuffrè, 2010, p. 486; VIGANÒ, Francesco, "Il rapporto di causalità nella giurisprudenza penale a dieci anni dalla sentenza Franzese”, Dir. pen. cont., $\mathrm{N}^{\circ} 3$ (2013), p. 23; ZIRULIA, "Caso Eternit", cit. nota n 13, p. 503.

${ }^{26}$ Para esta crítica cf. en particular SERENI, Causalità e responsabilità penale, cit. nota $\mathrm{n}^{\circ} 25$, p. 358 ; D'ALESSANDRO, “Art. 40", cit. nota n 25, p. 412; BARTOLI, Il problema della causalità penale, cit. nota $\mathrm{n}^{\circ} 25$, pp. 83 y ss.

${ }^{27}$ Cfr. MASERA, Accertamento, cit. nota ${ }^{\circ} 21$, cap. 2 (Affidabilità, metodologia e contenuto euristico delle ricerche epidemiologiche), pp. 105-178.
} 
Polít. crim. Vol. 12, No 23 (Julio 2017), Art. 12, pp. 428-452.

[http://www.politicacriminal.cl/Vol_12/n_23/Vol12N23A12.pdf]

terapéuticos, así como la evaluación del peligro de una sustancia) se basa precisamente en métodos estadísticos y epidemiológicos, cuya fiabilidad nadie cuestiona con seriedad. Por otra parte, incluso la jurisprudencia tradicional sostiene el posible uso de los estudios epidemiológicos para establecer el nexo de causalidad general. Dicho uso no podría justificarse si no se considera que estos estudios son fiables, así como los de otras disciplinas científicas.

Una cosa es hacer alusión a las dificultades que puedan surgir en la evaluación de la fiabilidad de un estudio epidemiológico en particular, y otra es dudar de la fiabilidad de la epidemiología en su conjunto. Mi razonamiento con respecto a la determinación alternativa evidentemente se basa en el supuesto de que, en este caso, el juez ha establecido con certeza razonable la fiabilidad del estudio subyacente a la evidencia del exceso de mortalidad: si se cumple esta condición, es legítimo sostener que la relación causal sobre la población debe considerarse establecida; sobre todo, con relación a los estrictos estándares de evidencia propios del proceso penal.

Otra crítica contraria a mi posición es la que considera que esta llevaría subrepticiamente al derrocamiento del modelo tradicional de establecimiento de la causalidad: sólo se trataría de una renovación de la teoría del aumento del riesgo adoptada por la jurisprudencia de los años noventa y abandonada definitivamente a partir del fallo Franzese de la Corte de Casación de $2002^{28}$.

En realidad, se trata de una crítica a la que respondí previamente en la monografía publicada en $2007^{29}$. El uso de evidencia epidemiológica para fundar la relación etiológica en un caso particular, como en la orientación del aumento del riesgo, implica en efecto el abandono del modelo de la conditio sine qua non, reemplazado por el criterio pronóstico del aumento del riesgo. Desde mi perspectiva, el elemento epidemiológico se utiliza para establecer la relación de causalidad, pero no con respecto al hecho singular, sino en relación con el exceso de mortalidad: con relación a este hecho diferente, el paradigma de la conditio sine qua non elaborado por Franzese no sufre ninguna distorsión, ya que a la comprobación de la capacidad de la sustancia para causar algunas patologías (que agotaba el establecimiento etiológico en el paradigma del aumento del riesgo) le sigue la constatación, dentro de la población específica objeto de análisis, de que la sustancia realmente ha provocado este incremento, sin que se haya presentado ninguna explicación alternativa plausible para el exceso. Por tanto, no se trata de una evaluación ex ante, sino de una evaluación ex post que garantiza el cumplimiento del principio de responsabilidad penal personal, imputando al autor únicamente la parte de los hechos que él ciertamente ha causado. Si la evaluación contrafáctica de la conditio sine qua non no se relaciona con el hecho singular, sino con el exceso de mortalidad, la evidencia epidemiológica es capaz de

\footnotetext{
28 En este sentido, cf. GARGANI, "La 'flessibilizzazione' giurisprudenziale", cit. nota n 25, p. 397; MANNA, "I rapporti tra sapere scientifico", cit. nota $\mathrm{n}^{\circ} 25$, p. 3636; SERENI, Causalità e responsabilità penale, cit. nota $\mathrm{n}^{\circ} 25$, p. 359.

${ }^{29}$ Cfr. MASERA, Accertamento, cit. nota $\mathrm{n}^{\circ}$ 21, cap. 6, par. 4.1, titulado "Differenze tra l'individuazione alternativa della vittima e la teoria dell'aumento del rischio" (pp. 423-429).
} 
MASERA, Luca. "Evidencia epidemiológica de un aumento de mortalidad y responsabilidad penal. En busca de una clasificación penal para una nueva categoría epistemológica".

garantizar un establecimiento etiológico fiable según la lógica generalmente utilizada por la jurisprudencia a partir del fallo Franzese.

Como apoyo a mi tesis, en primer lugar cabe resaltar una reciente contribución que, destacando que el elemento de exceso de mortalidad indica que personas de carne y hueso murieron precisamente debido a la exposición, no ve ningún obstáculo para incriminar el delito de homicidio o lesiones, ya que "las normas no imponen en sí la identificación de la víctima, sino que simplemente exigen que se reporte la evidencia de que el acusado causó la muerte o la enfermedad de una o más personas" ${ }^{30}$.

Por último, algunas observaciones sobre una reacción importante que generó la teoría fuera de la literatura jurídica.

En un libro publicado en 2009 por un epistemólogo influyente y especialista en temas relacionados con la evidencia jurídica de los hechos, hay un capítulo dedicado al tema de la determinación alternativa ${ }^{31}$. Tras un análisis formalizado con los métodos lógicos del fundamento de esta categoría, el autor concluye que "la determinación alternativa de la causalidad fotografía, de manera realista, una tipología de situación de incertidumbre cognitiva que se presenta de manera constante y inevitable en la investigación científica. Así pues, sería incorrecto concluir que la búsqueda de causalidad no alcanzó su objetivo simplemente porque no dio lugar a una determinación completa de los efectos" ${ }^{\text {"32 }}$. Desde la perspectiva de la lógica contrafáctica, que es el pilar de la teoría de la conditio sine qua non, el carácter alternativo de la determinación no compromete la fiabilidad de la imputación del hecho al comportamiento: así, en el plano de la evidencia jurídica, "el establecimiento de una separación de enunciados equiformes de causalidad es suficiente, en condiciones dadas, para probar una responsabilidad penal precisa, ${ }^{, 33}$.

\section{Conclusiones.}

1) El tema cuyas coordenadas esenciales hemos tratado en el presente trabajo actualmente es, para retomar el propósito de una influyente doctrina, de una "abrumadora actualidad científica y político-criminal ${ }^{, 34}$.

De hecho, desde hace años la epidemiología plantea un desafío para el penalista. Además del concepto tradicional de causa, entendida como una relación de conditio sine qua non entre un agente patógeno y la manifestación de una patología en un individuo, la

\footnotetext{
${ }^{30}$ VIGANÒ, "Il rapporto di causalità", cit. nota ${ }^{\circ} 25$, p. 25; en el mismo sentido cf. también ZIRULIA, "Caso Eternit", cit. nota n 13, p. 504 y DELLA BELLA, "Il problema del nesso causale", cit. nota n 25, p. 67.

${ }^{31}$ PIZZI, Claudio, Diritto, abduzione, prova, Milano: Giuffrè, 2009, cuyo capítulo VIII (p. 151-170) se titula "Accertamento alternativo e logica degli eventi".

${ }^{32}$ PIZZI, Diritto, abduzione, prova, cit. nota n ${ }^{\circ} 31$, p. 166.

${ }_{33}^{33}$ PIZZI, Diritto, abduzione, prova, cit. nota n ${ }^{\circ} 31$, p. 167.

${ }^{34}$ DONINI, Massimo, "Reati di pericolo e salute pubblica. Gli illeciti di prevenzione alimentare al crocevia della riforma penale", Riv. trim dir. pen. ec. $\mathrm{N}^{\circ}$ 1/2 (2013), p. 85.
} 
Polít. crim. Vol. 12, No 23 (Julio 2017), Art. 12, pp. 428-452.

[http://www.politicacriminal.cl/Vol_12/n_23/Vol12N23A12.pdf]

epidemiología ha introducido un nuevo concepto de causa con respecto a la relación entre un factor de riesgo y el aumento de la incidencia de una patología en una pluralidad (una población) de individuos. Hace ya más de cincuenta años que la ciencia médica reconoce la validez de este método de establecimiento de la causa a la que comúnmente reconocemos la capacidad de generar, sobre la base de poblaciones, resultados etiológicos bastante fiables. Las categorías de la imputación jurídica se desarrollaron cuando no existía este concepto de causa y, por ello, tienen dificultades en cuanto a la manera de expresar su contenido heurístico. De hecho, el concepto de causalidad tradicionalmente se considera como un sinónimo de la conditio sine qua non de un hecho singular: a nivel poblacional, es posible hablar de peligro, pero no de causalidad. La epidemiología introduce el concepto de exceso de mortalidad, que expresa una evaluación de la conditio sine qua non que no se refiere a un individuo, sino a una población de individuos. ¿El derecho penal es capaz, sin renunciar a sus principios fundamentales de garantismo, de incluir dentro de sus propias categorías conceptuales este nuevo concepto científico, o la evidencia de un daño a la población trasmitida por la ciencia epidemiológica está fuera del ámbito del derecho penal?

2) Como hemos comentado, la primera respuesta a esta pregunta proviene de la jurisprudencia de los años noventa, con la teoría del aumento del riesgo, pero esta respuesta es incorrecta. Las categorías de la imputación etiológica se desnaturalizan para permitir que la evidencia epidemiológica establezca un nexo de causalidad para el hecho singular, mientras que la especificidad heurística de tal disciplina consiste precisamente en establecer las relaciones etiológicas, no a nivel individual sino a nivel poblacional.

La reacción frente a esta posición no tardó en aparecer, primero en la doctrina y seguidamente en la jurisprudencia: la teoría según la cual la epidemiología "es útil pero no suficiente" afirma la verdad innegable de que esta ciencia no es capaz, por sí sola, de conducir a un establecimiento razonablemente certero de los nexos de causalidad individuales.

Esta conclusión destaca correctamente las limitaciones intrínsecas del método epidemiológico, pero no logra expresar su capacidad heurística específica. Afirmar que la epidemiología no es suficiente para establecer los nexos de causalidad individuales es correcto, pero esta constatación no tiene en cuenta lo que esta ciencia es capaz de establecer con certeza razonable: los nexos de causalidad sobre la base de poblaciones, en otras palabras, el exceso de mortalidad. La epidemiología no solo establece la peligrosidad de una sustancia para la salud, sino que también es capaz de estimar los efectos que esta sustancia ha generado en una población determinada, las muertes científicamente atribuibles a la sustancia: este elemento epistemológico fundamental desaparece por completo en la perspectiva del concepto "es útil, pero no suficiente", que reduce la evidencia epidemiológica a un mero indicador de peligro, omitiendo su capacidad para formular nexos de causalidad para hechos pasados, cuando estos hechos se formulan a nivel poblacional.

Las categorías del derecho obligan pues, según la visión tradicional, a afirmar que la constatación de que decenas o cientos de personas murieron a causa de una exposición no es suficiente para establecer la responsabilidad penal como homicidio, pese a que esta 
MASERA, Luca. "Evidencia epidemiológica de un aumento de mortalidad y responsabilidad penal. En busca de una clasificación penal para una nueva categoría epistemológica".

causalidad es científicamente cierta más allá de toda duda razonable. "El punto de vista del derecho penal debe prevalecer y no el de la epidemiología" ${ }^{35}$ : creemos que esta frase encarna perfectamente la que durante mucho tiempo (y quizás aún en la actualidad) se ha considerado como la opinión común de la doctrina jurídica italiana en la materia.

Los casos contemplados en este trabajo son los que precisamente revelan la fragilidad de dicha posición. Cuando a una población se le informa de que se han producido cientos de muertes en ella, y que éstas son ciertamente atribuibles a una sustancia dada, se crea una esperanza de justiciabilidad de la que el poder judicial difícilmente puede escapar. No se trata de adoptar un enfoque "justicialista" que convertirá el derecho penal en la panacea contra todos los males de la sociedad. Un empresario que negligentemente causa la muerte de un trabajador incurre en una sanción penal, mientras que a uno que causa la muerte de cientos de trabajadores que, según una razonable certeza científica, no habrían muerto sin esta exposición, no podría aplicársele una sanción penal, a menos que se hiciera una identificación unívoca de las víctimas de la exposición. Se trata de una conclusión absurda que expresa una injusticia insoportable para cualquier actor social que pretenda basar su actuación en criterios racionales. $\mathrm{O}$ bien negamos el hecho de que la epidemiología es una disciplina fiable a nivel abstracto, una afirmación que ningún científico serio estaría dispuesto a apoyar, o bien aceptamos que, si un estudio epidemiológico metodológicamente correcto confirma una correlación causal entre una sustancia y un aumento de la mortalidad, este elemento debe interesar a la justicia penal.

3) La jurisprudencia más reciente que hemos analizado en las páginas de este ensayo considera haber encontrado el instrumento adecuado para clasificar, en materia penal, este elemento heurístico dentro de los delitos dolosos contra la seguridad pública, pero esta conclusión parece insatisfactoria. La "vestimenta" que esta jurisprudencia ha confeccionado para "vestir", en materia penal, al elemento sobre el exceso de mortalidad, es demasiado estrecha y demasiado amplia a la vez. Es demasiado estrecha, ya que, desde el punto de vista del elemento objetivo, la clasificación jurídica elegida exige imputar al autor únicamente por el hecho de haber causado peligro a la salud pública, mientras que el exceso de mortalidad expresa la verificación de un daño a la vida y a la integridad física de un número significativo de personas. Es demasiado amplia, porque, en el plano subjetivo, para permitir la imposición de sanciones correspondientes a la gravedad del hecho cometido, comporta una interpretación demasiado amplia del elemento intencional del desastre.

Con todo, hemos asistido a una especie de trade-off entre el elemento objetivo y subjetivo del delito. Basta pensar en los casos Eternit o Ilva. Lo que hace que estos casos sean tan serios no es el elemento subjetivo especialmente censurable de los acusados: la falta de interés en la salud de los trabajadores reprochada a los acusados no se diferencia de la conducta de un empresario que, para ahorrar en seguridad en una obra de construcción, decide aplicar un sistema de seguridad insuficiente, causando la muerte de un trabajador. El elemento que destaca en todos estos casos es el gran número de víctimas involucradas:

\footnotetext{
${ }^{35}$ PERINI, Il concetto di rischio, cit. nota n ${ }^{\circ}$ 25, p. 495.
} 
Polít. crim. Vol. 12, No 23 (Julio 2017), Art. 12, pp. 428-452.

[http://www.politicacriminal.cl/Vol_12/n_23/Vol12N23A12.pdf]

estos casos son de gravedad excepcional desde la perspectiva del elemento objetivo, y no tanto del coeficiente subjetivo especialmente intenso de los empresarios.

Además, la elección de la clasificación operada por la jurisprudencia no da cuenta de las muertes, que se citan en los escritos de cargos o en las sentencias, sin que se les atribuya una importancia jurídica, ya que se trata de condenas por delitos de peligro. Si estos delitos hubiesen sido incriminados en su forma culposa, los procesos habrían dado lugar a un resultado absurdo, a saber, el establecimiento de la causalidad de cientos de muertes con penas muy ligeras (la pena máxima conforme al art. 449 del Código Penal italiano por desastre culposo es de cinco años). Para evitar tal aporía, el elemento intencional del delito de desastre doloso se interpretó muy ampliamente para permitir la aplicación de sanciones apropiadas para la gravedad de los hechos.

4) La otra solución disponible, no utilizada aún por la jurisprudencia ${ }^{36}$, consiste en reconducir, mediante la aplicación de la determinación alternativa, el elemento del exceso de mortalidad en los delitos de homicidio o lesiones. La evidencia epidemiológica confirma que una serie de individuos no habría muerto en ausencia de la exposición: de hecho, la clasificación como homicidio parecería ser la solución más razonable, la más acorde con el "famoso sentido común que debe caracterizar siempre a las construcciones jurídicas, incluyendo las más sofisticadas" ${ }^{37}$. Sin embargo, hasta ahora, ni la jurisprudencia ni la mayor parte de la doctrina han querido seguir este camino. En páginas anteriores ya se tuvo en cuenta las críticas (en nuestra opinión refutables) que se formularon contra mi intento de justificar la legitimidad de esta clasificación. Ahora quisiera identificar, más allá de los comentarios técnicos sobre la determinación alternativa, las que creo son las dificultades de fondo para aceptar el argumento según el cual la evidencia epidemiológica es suficiente para establecer la responsabilidad como homicidio.

La idea de una incriminación por homicidio en ausencia de una identificación unívoca de la víctima cuestiona aquello que, a nivel de precomprensión de las categorías jurídicas, se muestra en dos postulados. El primer postulado, que considera que la causalidad solo puede tener como objeto relaciones de consecuencia con los hechos singulares, está bien arraigado en la opinión común del penalista. Sin embargo, como hemos dicho anteriormente, ha sido desmentido con respecto a sus prerrequisitos epistemológicos y ya ha sido cuestionado por la propia jurisprudencia: hemos visto cómo en la sentencia de la Corte de Apelación de Turín se aceptó que el contenido de garantismo de la condición sine qua non permanece sin cambios cuando, tras una evaluación ex post para excluir la existencia de explicaciones alternativas, se imputa el haber causado no solo un hecho singular, sino un exceso de mortalidad en la población.

\footnotetext{
${ }^{36}$ De hecho, el fallo de la Corte de Casación en el caso Eternit se refiere expresamente a la determinación alternativa de la víctima, pero, dado que el juicio se basaba en la imputación de desastre, la Corte no podía tomar posición sobre la posibilidad de utilizar este instrumento para una responsabilidad por el cargo de homicidio.

${ }^{37}$ VIGANÒ, "Il rapporto di causalità", cit. nota $n^{\circ}$ 25, p. 25, apoyando mi postura.
} 
MASERA, Luca. "Evidencia epidemiológica de un aumento de mortalidad y responsabilidad penal. En busca de una clasificación penal para una nueva categoría epistemológica".

El segundo postulado sostiene que la condena por homicidio requiere una identificación unívoca de la víctima: sin el "nombre y apellido" de la persona cuya muerte ha sido causada, la incriminación por homicidio es imposible. Se trata de un postulado real en el sentido de que la doctrina y la jurisprudencia aceptan irrevocablemente su validez, sin dar ninguna explicación racional y basada en la ley. El único argumento concreto consiste en afirmar que, al tratarse de normas que protegen los intereses individuales, es esencial identificar unívocamente al titular del interés violado.

Sin embargo, se trata de un argumento muy débil. Desde el punto de vista de la interpretación estricta de la ley, las normas en materia de homicidio sancionan el hecho de haber causado la muerte de una o más personas, pero en ningún caso requieren la identificación de la víctima. Tomemos, por ejemplo, el caso de un barco de inmigrantes que se hunde en el mar Mediterráneo porque los traficantes de hombres que habían organizado el viaje sobrecargaron el barco. ¿Podría alguien pensar razonablemente que estos individuos no podrían ser acusados de homicidio a menos que se reconstruya la identidad de las víctimas que yacen en el fondo del mar? ¿Alguien podría afirmar que, a pesar de la certeza de que seres humanos han muerto a causa de la conducta de los acusados, no son responsables del homicidio a menos que se especifique el nombre y apellido de las víctimas?

En realidad, el postulado de la identificación necesaria de las víctimas surge del hecho de que, en general, si no hay prueba certera con respecto a la persona que fue asesinada, no es posible establecer con certeza que alguien fue asesinado. Pero cuando, como en el caso de la evidencia epidemiológica, existe la certeza de que un comportamiento ha causado cierto número de víctimas, ningún obstáculo real evita la responsabilidad por homicidio: lo que exigen las normas en materia de homicidio es que alguien haya fallecido a causa de una conducta humana, que personas hayan perdido la vida, pero no exigen que sea posible identificar a las víctimas.

5) Para una discusión más extensa sobre estos argumentos, remito a mi monografía, especialmente con relación a los perfiles sobre la capacidad técnica de aplicar concretamente mi tesis en el contexto de un proceso. Este ensayo está llegando a su fin, así que es el momento de concluir rápidamente.

En cuanto a la elección del camino que se debe tomar para atribuir importancia penal a la evidencia epidemiológica, la jurisprudencia ha elegido el camino más fácil. Evidentemente, es más fácil atribuir el exceso de mortalidad a una infracción de contornos amplios y poco definidos como es el desastre, en lugar de apoyar una clasificación como homicidio, que requeriría cuestionar convicciones profundamente arraigadas (aunque infundadas, en mi modesta opinión) con relación a un concepto general muy complejo, como la causalidad.

No obstante, la clasificación de homicidio es la única que permite, conforme a los principios de garantía subyacentes a un sistema penal liberal, dar al elemento científico del exceso de mortalidad su justa clasificación legal: no solo es un peligro para la salud pública, sino un daño en la vida de las personas. Cuando la ciencia afirma que se ha 
Polít. crim. Vol. 12, No 23 (Julio 2017), Art. 12, pp. 428-452.

[http://www.politicacriminal.cl/Vol_12/n_23/Vol12N23A12.pdf]

producido un exceso de mortalidad en una población como resultado de una producción industrial, esto no significa que solo se ha producido un peligro para la salud de la población, sino que también murieron personas de carne y hueso a raíz de este hecho: el camino necesario para que el derecho penal incluya este elemento científico dentro de sus categorías aún está lejos de acabar. 
MASERA, Luca. "Evidencia epidemiológica de un aumento de mortalidad y responsabilidad penal. En busca de una clasificación penal para una nueva categoría epistemológica".

\section{BIBLIOGRAFÍA}

BARTOLI, Roberto, Il problema della causalità penale - Dai modelli unitari al modello differenziato, Torino: Giappichelli, 2010.

"La recente evoluzione giurisprudenziale sul nesso causale nelle malattie professionali da amianto", Dir. pen. cont., $\mathrm{N}^{\circ}$ 3-4 (2014).

BRUSCO, Carlo, Il rapporto di causalità - Prassi ed orientamenti, Milano: Giuffrè, 2012.

CENTONZE, Francesco, "Il problema dell'accertamento del nesso di causalità tra esposizione professionale ad amianto e mesotelioma pleurico", Riv. it med. leg. $\mathrm{N}^{\circ} 3$ (2012), p. 1523.

D'ALESSANDRO, Francesco, “Art. 40”, en: DOLCINI, Emilio; MARINUCCI, Giorgio (Dirs.), Codice penale commentato, Milano: IPSOA, III ed., 2011, p. 411.

DELLA BELLA, Angela, "Il problema del nesso causale nel sistema penale e processuale”, en: SMURAGLIA, Carlo (Dir.), Le malattie da lavoro, Milano: Hoepli, 2008, p. 66.

DI GIOVINE, Ombretta, "Probabilità statistica e probabilità logica nell'accertamento del nesso di causalità”, Cass. pen., $\mathrm{N}^{\circ} 5$ (2008), p. 2183.

DONINI, Massimo, "La causalità omissiva e l'imputazione "per l'aumento del rischio" Significato teorico e pratico delle tendenze attuali in tema di accertamenti eziologici probabilistici e decorsi causali ipotetici", Riv. it. dir. proc. pen., 1999, p. 32.

, "Imputazione oggettiva dell'evento", Enc. dir., Annali, III, Milano: Giuffrè, 2010, p. 703.

, "Il garantismo della condicio sine qua non e il prezzo del suo abbandono. Contributo all'analisi dei rapporti fra causalità e imputazione", Riv. it. dir. proc. pen. Vol. 2 (2011), p. 514.

, "Reati di pericolo e salute pubblica. Gli illeciti di prevenzione alimentare al crocevia della riforma penale", Riv. trim dir. pen. ec. $\mathrm{N}^{\circ} 1 / 2$ (2013), p. 85.

ESER, Albin, "Anhang zu $\S 1$ : Wahlfeststellung”, en: SCHÖNKE, Adolf; SCHRÖDER, Horst (Dirs.), Strafgesetzbuch Kommentar, München: C.H. Beck, XXV ed., 1997, § 58 ss.

GARGANI, Alberto, "La 'flessibilizzazione' giurisprudenziale delle categorie classiche del reato di fronte alle esigenze di controllo penale delle nuove fenomenologie di rischio", Leg. pen., 2011, p. 397.

GREEN, Michael; FREEDMAN, Michael; GORDIS, Leon, "Reference Guide on Epidemiology", en Reference Manual of Scientific Evidence, publicado por el Federal Judicial Center, III ed., 2011, p. 551 s.

MANNA, Adelmo, "I rapporti tra sapere scientifico e sapere giudiziario", Cass. pen. Vol. XLIX (2009), p. 3636.

MASERA, Luca, "Nesso di causalità e malattie professionali e nella giurisprudenza penale: un difficile equilibrio tra tutela dei lavoratori e garanzie dell'imputato", en: GUAGLIANONE, Luciana; MALZANI, Francesca (Dirs.), Come cambia l'ambiente di lavoro, Milano: Giuffrè, 2007, p. 156.

- Accertamento alternativo ed evidenza epidemiologica nel diritto penale Gestione del dubbio e profili causali, Milano: Giuffrè, 2007. 
Polít. crim. Vol. 12, № 23 (Julio 2017), Art. 12, pp. 428-452.

[http://www.politicacriminal.cl/Vol_12/n_23/Vol12N23A12.pdf]

PALIERO, Carlo Enrico, “La causalità dell'omissione: formule concettuali e paradigmi prasseologici”, Riv. it. med. leg., 1992, p. 821.

PALMISANO, Stefano, "Del "diritto tiranno" - Epitome parziale di un'indagine su cittadini già al di sopra di ogni sospetto", Quest. giust. N 2 (2014), p. 89.

PERINI, Chiara, Il concetto di rischio nel diritto penale moderno, Milano: Giuffrè, 2010.

PIZZI, Claudio, Diritto, abduzione, prova, Milano: Giuffrè, 2009.

SERENI, Andrea, Causalità e responsabilità penale, Torino: Giappichelli, 2008.

STELLA, Federico, Giustizia e modernità - La protezione dell'innocente e la tutela delle vittime, Milano: Giuffrè, 2001.

TRÖNDLE, Herbert; FISCHER, Thomas, “§ 1", en: TRÖNDLE, Herbert; FISCHER, Thomas (Eds.), Strafgesetzbuch und Nebengesetze, München: C.H. Beck, XLIX ed., $1999, \S 12$ ss.

VIGANÒ, Francesco, "Il rapporto di causalità nella giurisprudenza penale a dieci anni dalla sentenza Franzese", Dir. pen. cont. № 3 (2013).

ZIRULIA, Stefano, “Ancora oscillazioni nella giurisprudenza di legittimità sulle "morti da amianto"", Dir. pen. cont., 11.10.2012.

, "Caso Eternit: luci ed ombre nella sentenza di condanna in primo grado", Riv. it. dir. proc. pen., Vol. 56, $\mathrm{N}^{\circ} 1$ (2013), p. 489. 